\title{
Community-Based Intersectionality: The Changing Public Services Project
}

\author{
Tammy Findlay, Michelle Cohen, Mary-Dan Johnston
}

\begin{abstract}
The paper reflects on a changing public service project regarding women and intersectional analysis in Halifax, Canada. The project sought to facilitate collective mobilizations to challenge austerity and to imagine public services that meet the needs of the citizens who use them, and the workers that provide them. We provide an overview of the project, and then explore our attempt at adapting "multistrand" intersectional policy analysis (Hankivsky \& Cormier, 2011) to a community-based context. In considering the challenges and opportunities associated with this work, the paper concludes that the changing public service project created space for an innovative approach to community-based research that can guide both participatory policy analysis and collective action.
\end{abstract}

KEYWORDS intersectionality, women, community, policy analysis

For inspiration on new kinds of struggles for social justice, we can look to what Cho, Crenshaw and McCall (2013) refer to as "political intersectionality," and what Chun, Lipsitz and Shin (2013) call "social movement intersectionality (p. 917)." Intersectional analysis demands that not only policy makers, but also activists work to: avoid prioritizing one social category over another; break down the silos between policies; engage in reflexivity, self-awareness and scrutiny of privilege; and attend to lived experience and knowledge production (CRIAW, 2006; Hankivsky \& Cormier, 2011; Chun, Lipsitz \& Shin, 2013). At its heart, intersectionality is a means of collective struggle that "can inform connections across privilege as well as subordination to better facilitate meaningful collaboration and political action" (Cho, Crenshaw, \& McCall, 2013, p. 804).

In this paper, we reflect on a project called "Changing Public Services: Women and Intersectional Analysis" (CPS). CPS was a partnership between the Canadian Research Institute for the Advancement of Women (CRIAW), five national public sector labour unions, and five universities. As the co-initiators and coordinator of the Nova Scotia regional cluster of the project, we consider the challenges and opportunities for building capacity for equality research and organizing. By analyzing CPS as an experiment in community-based intersectionality, the paper asks: How can academics, labour unionists, public sector workers, community activists, and service users, work together to understand and challenge the impact of austerity and 
restructuring of public services on diverse groups of women? Our project positions the researcher not as a neutral and 'objective' observer, but rather as an active subject with an explicitly political purpose. The stated objective of CPS is to support collective mobilizations locally and nationally.

We begin with an overview of the national CPS project and its overarching structure. We then turn to the development of the Nova Scotia cluster, and discuss our attempt at adapting "multistrand" intersectional policy analysis (Hankivsky \& Cormier, 2011) to a communitybased context. This methodology takes a systematic approach to integrating intersectionality into every stage of policy-making, and requires that at each stage, questions of inclusion, representation, and equity are prioritized. Its highlights include: the use of community-based research in policy-making; consciously "putting oneself in someone else's shoes;" identifying commonalities across differently situated groups; and collective visioning of alternatives (Hankivsky \& Cormier, 2011). While the multistrand approach was developed as a tool of formal policy-making, we used it to support local political organizing.

We argue that there are many challenges to carrying out this work including: power differentials; time and resource constraints; local internal political differences; and academic inaccessibility. However, it has created space for an innovative approach to community-based research that can guide participatory policy analysis and collective action.

\section{Changing Public Services}

Feminist research has shown that women are disproportionately and negatively affected by neoliberal restructuring of public services and austerity agendas (Brodie \& Bakker, 2007; Cohen \& Pulkingham, 2009). However, we know much less about the differential implications for women in varied social locations and their strategies of resistance. Much more work is needed to explore and develop the theories and methods of intersectionality to understand experiences with public services in Canada.

Changing Public Services was a four-year project, funded through a Social Sciences and Humanities Research Council (SSHRC) partnership development grant, to identify the impacts of changes in public policy, public sector employment, program delivery, and governance, on diverse groups of women in Canada. The overall objective was to create a pan-Canadian, bilingual network which would bring together community groups, unions, governments, and individuals to highlight and respond to impacts of changes in public services since the 2008 financial crisis, and to ensure future changes are effective and appropriate for service users and providers. The first phase began with initiating a network, made up of four regional clusters - Nova Scotia, the National Capital Region, Saskatoon, and Lower Mainland British Columbia — to accomplish the following:

1) identify and develop tools, connections, agreements, and strategies for tracking changes to public services and public sector employment;

2) use participatory tools to track and analyze the impacts of these changes on diverse groups of women over time (e.g. mapping, media analysis, storytelling); 
3) identify combined and cascading impacts as a result of municipal, provincial and federal changes; and

4) collectively prioritize areas for further research and action.

The project was a collaboration between the Canadian Research Institute for the Advancement of Women (CRIAW), the Canadian Labour Congress (CLC), the Canadian Union of Public Employees (CUPE), the Canadian Union of Postal Workers (CUPW), the Public Service Alliance of Canada (PSAC), and the Canadian Association of University Teachers (CAUT). It was hosted at the University of Guelph and involved several other Canadian universities.

The research team members included a national project manager, a leadership circle of academic and labour partners, an administrative assistant, and two co-initiators and a coordinator for each regional cluster. The four clusters of the CPS network identified questions that were important in the region, and to the regional partners. Using the lens of intersectionality, each cluster foregrounded groups of women who may face unique barriers and opportunities (e.g., women with disabilities, immigrant women, women in rural areas) in the face of changing public services. Clusters developed their own scope and focus, which varied throughout the country.

Each cluster began by meeting with community partners to name and discuss concerns about the impacts of particular policy, program, and employment changes on women with diverse identities. These discussions were aided by ongoing national research through CRIAW including a study of the impacts of precarious employment on women in the public sector, an intersectional statistical analysis of women and employment, and a systematic scoping review on the impacts of changing public services on women, with emphasis on young women, women with disabilities, Indigenous women, lone parents, and immigrant women. Within and across regions, CPS developed tools and participatory processes to identify and track changing public services and their impacts. The objective was to increase all women's access to public services, and to help ensure diverse women can influence and inform public services. Moving forward, we aim to develop future research and action projects in our local communities. CPS has been communicating and disseminating the findings of this work broadly through fact sheets, articles, presentations, and social media.

\section{The Nova Scotia Cluster}

The network in Nova Scotia came together after a list was comprised of a variety of nonprofit, social services organizations and unions whose work deals with the provision of, receipt of, and/or advocacy for, public services. A call out for partners to join our regional steering committee was originally sent to over 30 organizations and unions with representatives based primarily, but not exclusively, in Halifax. The groups were chosen specifically to give as much social and cultural diversity as possible. Although we were originally tagged as the "Atlantic" regional centre for CPS, it was clear early on that we did not have the resources to reach beyond Nova Scotia to other Atlantic provinces. In fact, the steering committee was mostly 
Halifax-based, and even though many of the organizations involved are provincial, or even national, their head office is located in the Halifax region.

There were representatives from the following organizations:

- Public Service Alliance of Canada (PSAC)

- Canadian Union of Public Employees (CUPE)

- Canadian Federation of University Women (CFUW)

- Community Society to End Poverty in NS

- Service Employees International Union (SEIU)

- Nova Scotia Government \& General Employees Union (NSGEU)

- Nova Scotia Teacher's Union (NSTU)

- Nova Scotia Nurses Union (NSNU)

- Canadian Federation of Students (CFS)

- Students Nova Scotia

- Canadian Centre for Policy Alternatives (CCPA)

- Women's Centres Connect Nova Scotia

- Women's Action Alliance for Change Nova Scotia (WACNS)

- Halifax YWCA

- Adsum House for Women and Children

- Dalhousie Legal Aid

- Avalon Sexual Assault Centre

- Nancy's Chair in Women's Studies, Mount Saint Vincent University (MSVU)

- Nova Scotia Citizens' Health Care Network

- Alexa McDonough Institute for Women, Gender and Social Justice

As will be elaborated later on, these partners were engaged to varying degrees. There was also a sub-committee that acted as a working group to address logistical aspects of the project. The cluster was hosted by the Alexa McDonough Institute for Women, Gender and Social Justice (AMI), a research and community collaboration hub at MSVU, which is well-suited to the intersectional, community-based outlook of CPS.

\section{Intersectionality in Community}

Intersectionality is at once a theory, a research methodology, and a strategic framework. Intersectional policy analysis operates at all three levels. Hankivsky and Cormier (2011) explain that,

[the] goal of intersectionality policy analysis is to identify and address 'the way specific acts and policies address the inequalities experienced by various social groups,' taking into account that social identities such as race, class, gender, ability, geography, and age interact to form unique meanings and complex experiences within and between groups in society (p. 217). 
Intersectionality is a tool that can applied by policy analysts and decision-makers, as well as by grassroots activists and social movements (Cho, Crenshaw \& McCall, 2013; Chun, Lipsitz \& Shin, 2013). CRIAW (2006) has developed Intersectional Feminist Frameworks (IFFs) that can "inform government policy and organizing strategies for activists" (p. 22, emphasis ours). Chun, Lipsitz and Shin (2013) refer to "social movement intersectionality" to highlight "the action imperatives of intersectionality” (pp. 917, 921) and Cho, Crenshaw, and McCall (2013) employ "political intersectionality." They explain that,

The concept of 'political intersectionality' reflects a dual concern for resisting the systemic forces that significantly shape the differential life chances of intersectionality's subjects and for reshaping modes of resistance beyond allegedly universal, single-axis approaches. Political intersectionality provides an applied dimension to the insights of structural intersectionality by offering a framework for contesting power and thereby linking theory to existent and emergent social and political struggles. This praxis orientation demands that the realm of practice always already inform the work of theorists (p. 800).

Putting intersectional analysis into practice demands that activists/researchers avoid prioritizing one social category over another; break down the silos between policies; engage in reflexivity, self-awareness and scrutiny of privilege; and are attentive to lived experience and knowledge production (CRIAW, 2006; Clark et al., 2010; Dhamoon \& Hankivsky, 2011; Hankivsky \& Cormier, 2011; Hankivsky et al., 2012; Chun, Lipsitz \& Shin, 2013). In an effort to operationalize these principles, research assistants at CPS put together an extensive overview of creative, intersectional, participatory research methods that was distributed to all of the regional clusters. These ranged from visual mapping (Waddell, 2012), to collaborative narrative (Four Worlds Centre for Development Learning, 2000), to digital storytelling (Gregory et al., 2008). Because it fit well with the spirit of our steering committee's interests, we proposed the multi-strand approach to public policy analysis (Parken \& Young, 2007; Hankivsky \& Cormier, 2011).

\section{Multistrand Intersectional Policy Analysis}

The multi-strand approach is an intersectional research methodology that involves stakeholders from diverse social locations (gender, race/ethnicity, ability, religion/belief, age, and sexual orientation). It is an inclusive method capable of promoting equality through all stages of public policy: mapping, visioning, road testing, and monitoring and evaluation (Parken \& Young, 2007; Hankinvsky \& Cormier, 2011). Its various stages are outlined in the figure by Parken and Young (2007) on the following page.

In the first stage, Mapping, the participants take stock of who is involved and what they already know about the policy area. They share information from multiple perspectives. In the second stage, they engage in Visioning. They identify commonalities and solutions in order to establish what should be done. The third step is Road Testing, which demands that 
participants actively consider how others would be affected by proposed policy solutions and to put themselves in the position of others. Monitoring and Evaluation, the final stage, involves reflecting on how to determine if policies are working and identifying equality indicators.

Two of these components were seen as especially promising for our purposes. Visioning, as it emphasizes imagining alternatives, is key to the social change focus of our project. As detailed earlier, one of the key objectives of CPS is to create a network for national and regional action. One of the other main elements, Road Testing, asks participants to put themselves "in someone else's shoes," which spoke directly to the essence of the conversations that were unfolding at our table.

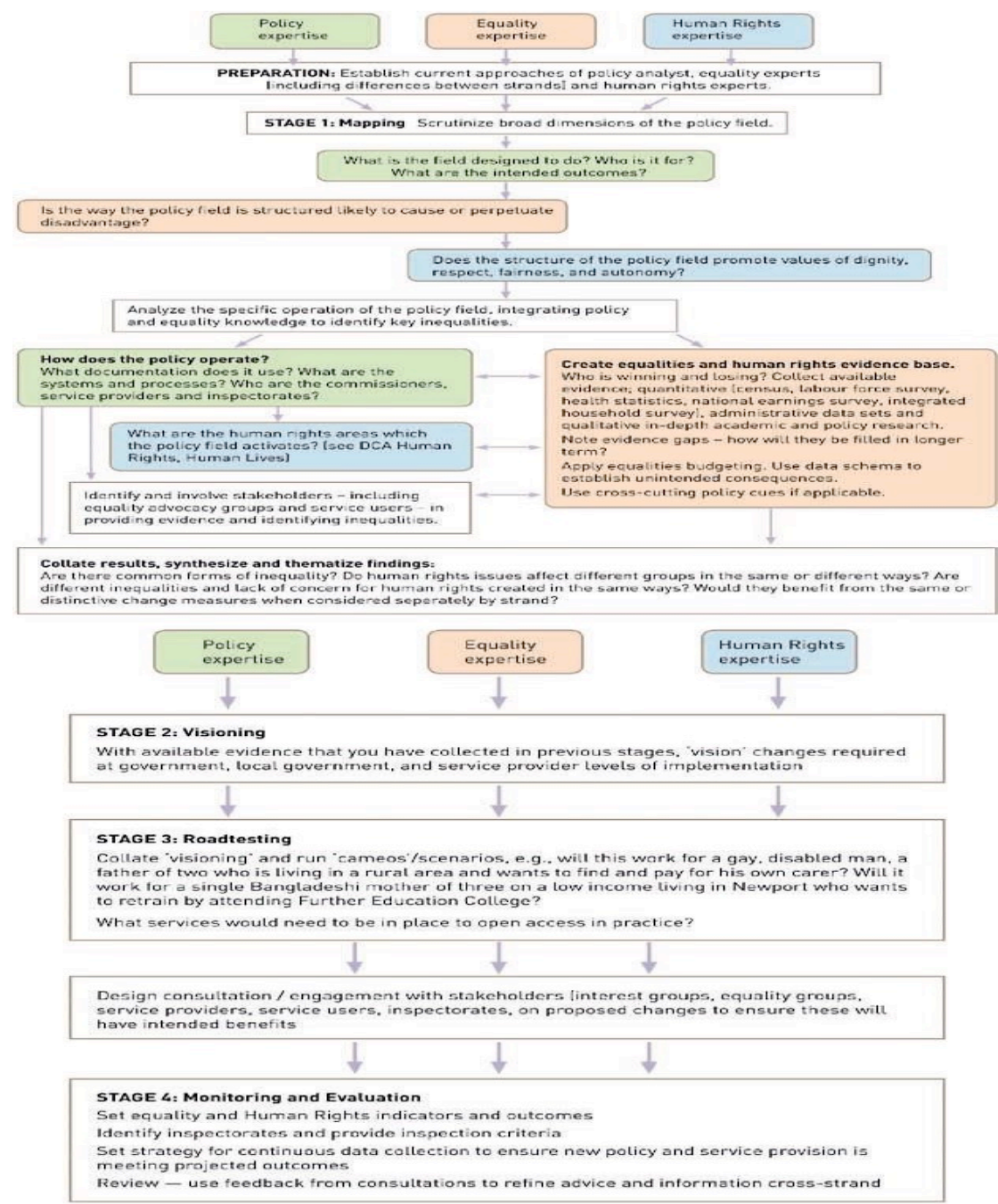

Figure 1. Multistrand Intersectional Policy Analysis, Parken and Young, 2007 
At our very first meeting, we began with a general discussion of what we mean by public services and how changing public services are affecting our communities. One of our steering committee members, Fiona Traynor, who has extensive experience working in legal aid, made a comment that she wished there were opportunities for genuine discussion between the case workers who provide services and the recipients of income assistance who rely on services, as both are negatively impacted by restructuring and austerity. What started out as a spontaneous remark, we soon realized, actually got to the heart of what we were trying to do with Changing Public Services project, and had the potential for many other conversations including those between nurses and patients, or students, parents and teachers. It looked at public policy from various angles: public sector workers; service users; and the voluntary sector. And it asked us to engage in dialogue across differences in order to identify commonalities, bridge divides and build solidarity.

When it came to the question of how we would actually organize this, we decided that the multi-strand approach could be adapted for community-based research to provide some structure to service provider-service user dialogues that also engaged with the voluntary sector. To get a sense of the pressing policy issues for our partners, we had a discussion based on three broad questions:

1) What are public services to you?

2) What do you think should be considered public services?

3) How is your organization/community affected by changing public services?

Several recurring themes emerged including health care, child care, post-secondary education, poverty and income insecurity. After this brainstorming session, the consensus was that we would move forward with income assistance ${ }^{1}$ as a pilot, with the goal of expanding this model in a range of other policy sectors if/when we were able to secure the larger partnership grant. The plan was to organize facilitated dialogues between public servants in the Department of Community Services, represented by the NSGEU, income assistance recipients, many of whom are being organized locally through Nova Scotia ACORN, and voluntary sector agencies and advocates. Once it became clear that this design might initially be too ambitious and confrontational, it was revised so that we would begin with separate, internal discussions among the various groups, and aspire to some joint cross-conversations later on, as trust was built. Our next task would be to invite some first-voice representatives from the income assistance community to join the steering committee and help us make concrete plans about how to structure the discussions and which questions to pose.

Here it might be worth stopping for a moment to map the provincial political terrain, as circumstances intervened that affected our research partnership and plans. On October 2, 2014 Liberal Premier Stephen McNeil brought about healthcare restructuring writ large with the passing of the Health Authorities Act (Bill 1). A highly partisan attack on labour, the Liberals tabled Bill 1 designating a central bargaining structure for all Nova Scotia healthcare

\footnotetext{
${ }^{1}$ With much debate about whether we should refer to 'income assistance,' 'social assistance,' or 'income security.'
} 
workers, attempting to dictate 'who goes where' in the process. Bill 1 substantially weakened the Nova Scotia Government Employees Union (NSGEU) and the Canadian Union of Public Employees (CUPE), both whom support the NDP, while bolstering the Nova Scotia Nurses' Union (NSNU), who support the Liberals — pitting union against union.

All three of these unions are partners in the CPS project and their divisions were highlighted during the arbitration process over Bill 1. In arbitration, CUPE was arguing that central to their work as a decentralized social union organization, are greater opportunities for women to engage politically (both internally and externally). CUPE maintained that their members would likely lose out on leadership roles if forced to join with another union. The provincial government was succeeding in instigating strife among labour.

Then, after a much publicized and mandated mediation session in the spring and summer of 2014, together the four unions figured out a way to deliver what the province wanted through a multi-union bargaining structure, without divvying up its respective membership. The government turned down this proposal insisting upon carving up labour representation as it saw fit. In January, the Supreme Court of Canada added further drama, coming down with two important rulings. The Saskatchewan Federation of Labour and the Mounted Police Association of Ontario cases substantially bolstered fundamental rights for unions, ultimately pulling the rug out from Liberals by underscoring people's freedom to choose their own union and bargain freely. Followed by several attempts by the Health Minister and the Premier to "fire" an arbitrator retained by multiple parties, the unions were approached with an offer from the Liberals. On March 13, 2015 an agreement was reached to form a Council of Unions for the purposes of negotiating collective agreements for healthcare workers. The government had to accept a form of multi-union bargaining association - the same idea the unions proposed the previous summer.

As a result of Bill 1, which had threatened to divide labour in the province, these four unions are now inexorably linked. The nature of belonging to a union broadened for all four organizations as they were confronted with what the future might hold for the labour movement collectively if their solidarity was undermined. Ross (2008) argues that "a coalition among likeminded leaders and members must be forged to fight not only for socially progressive policies but also for a richer experience of union democracy that will raise the expectations workers have of their own and other institutions" (p. 150). And this was reflected in the investments and interests our labour partners have in this project that is now stronger moving forward.

In the short term though, understandably, throughout the highs and lows of the Bill 1 saga, participation in CPS ebbed and flowed. Since Nova Scotia Government \& General Employees Union had been absent from the process over several meetings, preoccupied with the Bill 1 fight, we needed to reconnect with these partners, as the entire project rested on the participation of their members. In doing so, it became clear quite quickly that access to public sector workers would be difficult as the employer's expectations of confidentiality would make candor about their workplace challenges and possible personal contact with 'clients,' nearly impossible. We were facing the irony that the exact barriers to communication we were hoping

Engaged Scholar Journal: Community-Engaged Research, Teaching, and Learning 
to break down were preventing us from doing so.

This raises a broader concern about the ability of researchers to gain access to public servants. There is much rhetoric among government agencies, departments, administrators and practitioners, lately about public sector renewal, reform, innovation, and transformation. It is a priority area for the Institute of Public Administration of Canada (IPAC), the Public Service Commission of Canada, and the Clerk of the Privy Council (Canada, 2008, 2012 and 2014; Ontario, 2012; IPAC, 2013). Other countries and global organizations, including the International Centre for Parliamentary Studies (ICPS), the United Nations Economic Commission for Africa (UNECA), the World Bank, and RIPA International, are also interested in public sector reform and governance (U.N., 2010; ICPS, 2012). The crux of this discourse is that the 'new' civil service will need to directly engage with citizens and work in partnerships. Strangely, this is occurring when there has been unprecedented political interference, and cuts to public sector research in Canada (Voices-Voix, n.d; PIPSC, n.d.). Recently, numerous colleagues have described enormous difficulty getting access to federal and provincial public sector workers for interviews. There is an apparent lock-down on public sector participation in research and pervasive fear of job cuts and disciplinary action. The prospects for public sector 'renewal' are doubtful in such a climate.

There was certainly optimism in many circles that the defeat of Harper's Conservatives in the federal election would create a more open atmosphere for research and public service autonomy. The Trudeau Liberal Government's rhetoric about participation and inclusion as well as the resurrection of the long-form census were seen as positive signs. Nevertheless, there are now indications that this optimism is misplaced. Furthermore, the issues identified above continue to exist provincially and across political parties.

For the time being, we had to put the income assistance dialogues on hold, and revert to a more general discussion of public services in communities. We decided that organizational partners would host a dialogue session with their members/clients, where they would identify the issues they are encountering with public services (mapping) and share their ideas for change (visioning). We hope to return to the sector-specific approach in the future.

\section{The Discussion Groups}

The discussion groups were facilitated by CPS partners and typically held in a space that was familiar to participants between January 2016 and June 2016. CPS Nova Scotia Cluster research representatives were also in attendance and assisted the host facilitator. Nine discussions were held with: the Women with Disabilities Network, the Nova Scotia Nurses' Union, the NSGEU, the Canadian Federation of Students, Eastern Kings Community Health Board, CUPE Early Childhood Educators, the Immigrant and Migrant Women's Association, Indigenous women, and the Bridgewater Family Support Centre. Participants were asked to reflect on three questions:

1) Think of times in your life when you have relied on public services. Which public services have you relied on the most and why? (i.e. child care, education, health care, employment insurance, etc.) 
2) During the past ten years, have you noticed any changes in public services? (i.e. how available they are, how good they are, how much they cost, etc.)

3) Do you think there are any public services that are missing, or insufficient? If so, how should they change?

Participants also filled out a voluntary demographic questionnaire. These groups included 73 women from a diversity of backgrounds, communities and organizations. ${ }^{2}$ The conversations included those who self-identify as: Indigenous, non-Indigenous/settler, Canadian citizen, permanent resident immigrant, from a racialized group, from a non-racialized group, heterosexual, LGBT, female, transgender, with a disability, and without a disability. The participants spanned all age groups and were from low to high income levels. Some had children. They were primarily from the Halifax region, with some from other areas around the province. Some were employed, some were students, and some were unemployed. There were both public service workers and users.

These discussions yielded an enormous amount of data. ${ }^{3}$ An audio recording of each discussion was made with the consent of participants. Research assistants transcribed these recordings, and research team members conducted a qualitative thematic analysis, coding each transcript by hand and conferring on their findings. The focus group discussion questions were open ended, and designed to cast an especially wide net in order to capture a broad range of experiences and concerns from a diverse group of participants.

The findings were summarized at a public event, the the Women's Research and Action Forum, on October 5, 2016 at Mount Saint Vincent University. This event was designed to bring research participants, community representatives, researchers, and students together to discuss the initial findings of the Nova Scotia Cluster's work, debrief the process, and plan next steps through a follow-up project, Changing Public Engagement from the Ground Up. The Forum (facilitated by Corrie Melanson) helped participants "step into the shoes" of women in different social positions through simple exercises to foster empathy and understanding. Participants read verbatim quotations from the discussion groups aloud, and worked in small groups to talk about what in these stories sounded familiar, and which aspects they were surprised by. By spending time clarifying the similarities and differences between the assembled women, participants were able to engage in a fruitful conversation about what public services that worked for women in their diversity might look like, and how they might feel to use. The day's activities are recapped in the CPS Women's Research and Action Forum Report, by student project assistant, Jennifer O'Keefe, which is posted on our project website. ${ }^{4}$ The research is further analyzed and presented in a final project report, written by Mary-Dan Johnston, CPS Coordinator, also posted on the website.

\footnotetext{
2 One group included men.

${ }^{3}$ This paper focuses mainly on the procedural aspects of CPS. For a more fulsome review of the issues and themes from the study, see the summary report at: https://www.criaw-icref.ca/en/page/changing-public-services--nova-scotia-

${ }^{4}$ See: https://www.criaw-icref.ca/en/page/changing-public-services
} 
In addition to the final project report, locally, we produced three community-based tools: Ten Reasons Why Universality is Important in Public Services; 'Who Does What' in Public Services?; and Changing Public Services: Intersectionality and the Experiences of Women with Disabilities. All of these materials are posted on the CPS website, and were distributed at a celebration event in the fall of 2017.

\section{Challenges}

Intersectionality requires perpetual internal reflection about power and privilege. Therefore, the balance of power and influence at the table is something we needed to remain aware of constantly. We endeavored to create a network over a hierarchy. Two of us were 'coinitiators,' or convenors, rather than directors or leaders. The co-initiators were drawn from community (Michelle Cohen from the Canadian Union of Public Employees) and academia (Tammy Findlay from the Department of Political and Canadian Studies at Mount Saint Vincent University). We had a diverse group of local partner organizations and individuals on the steering committee who signed on as co-partners and researchers. Regional clusters had significant autonomy to set their own research plans. Nevertheless, there are formal national partners and a "leadership circle" that set the overall direction of research and make decisions about finances, and academics are often at an advantage in relationships with community.

One of the strengths of this project is the support offered by national labour unions, and the opportunity to build relationships between local labour and community groups. At the same time, the labour presence did implicitly guide decisions about research priorities and approaches. Labour provided financial and in-kind support for CPS. We met in their space (the local PSAC office). They had paid staff to devote to the project. For some at the table who work in, or volunteer for, struggling community-based organizations, they seemed to have some ambivalence about the role of labour and what might be viewed as its relatively privileged position. Certainly some of the relationship-building CPS intended to foster was to bridge this gap between labour and the voluntary sector. As discussed below, the project could also help to complicate the way we view power relations and to contest competitive politics.

Another difficulty is related to academic inaccessibility. During one of our meetings very early on, Michelle asked why we were referring to ourselves as a 'cluster.' She noted that many people would be turned off by such academic jargon. Therefore, in our steering committee meetings, we had to stress that words like 'cluster' are effective for the purposes of grant proposals, but that we should feel free to refer to ourselves in other, more preferable ways. In another example, it was raised by participants many times that the marker of the post-2008 financial crisis was arbitrary, as austerity and neoliberal restructuring have been negatively affecting public services for decades. This discussion occurred both in the national gathering for the project and in our local meetings. Again, we agreed that the 2008 moment was more useful for research grants than it is for lived realities on the ground. Even in the context of growing emphasis on 'practical research' and university-community partnerships, these issues speak to the continuing disconnect between the expectations for academic success (particularly around research funding) and the needs of the broader community. 
Related, academic participants have unique benefits of time and expertise that is both an asset and a liability. As seen below, academic resources can be shared in ways that can advance community development and social change. Nonetheless, scholars, even community-oriented ones, have research agendas and preferences they want to pursue. As Clark et al. (2010) suggest, "[i]t is important to recognize that research happens within institutions, embedded with hierarchies of privilege and that researchers attached to the university hold power in the research process" (p. 246). They stress that for university researchers, being part of an "intersectional research team" demands "reflecting on the location and position of themselves as academics" (Clark et al., 2010, p. 244).

University researchers also work according to different timelines, having the luxury of in-depth, inclusive discussion and careful deliberation. Many community collaborators want a quicker pace — less talk and more action. Standard academic processes are often quite foreign and slow-moving to those outside of a university setting. ${ }^{5} \mathrm{~A}$ good illustration is research ethics, which undoubtedly delays getting things going. And while designed to be comprehensive enough to protect participants from risk, being asked to sign a nine-page Collaboration Agreement document full of legalese (as was required for CPS) is pretty overwhelming and intimidating! Clark et al. (2010) point to the tension between protection and inclusion that is raised by university ethics procedures, arguing that ethics boards give precedence to the former over the latter. Their intervention also raises concerns about the lines of accountability. They assert that,

[e]thics is not something that we obtain from our funder or university REB [research ethics board] and then proceed to the research. Rather, we centralize the power of the community stakeholders by first engaging in a meaningful dialogue about the research ethics at a community level, and then move onto obtaining institutional approval. Through this process, we can better account for community-institutional power dynamics and consider ethical dilemmas that are apparent to community members but may be invisible within the institutional ethics process (p. 248).

This is very compatible with the inclinations of CPS. We soon learned though, that we could not really have a "meaningful dialogue" with community without first having ethics approval. As Clark et al. (2010) reveal, protection trumps inclusion. In the end, we struck a compromise where participants would become research collaborators, but this does limit initial input.

Other community-based researchers have identified similar challenges. The project Community First: Impacts of Community Engagement, was aimed at strengthening community-campus partnerships, and highlighting the "the needs, priorities, and expertise of the communities and community-based organizations involved" (Andrée, Findlay \& Peacock 2018). Researchers from one of the project's demonstration partners, the Community Food Sovereignty Hub, analyzed the "entrenched research practices that centre academic power

\footnotetext{
${ }^{5}$ Interestingly, Kepkiewicz, Levkoe, and Brynne (2018) found the opposite, with community partners wanting a slower pace with more time for relationship-building.
}

Engaged Scholar Journal: Community-Engaged Research, Teaching, and Learning 
over funding, timelines, and definitions of community" they encountered (Kepkiewicz, Levkoe, \& Brynne, 2018, p. 50). Dorow and Smith Acuña also emphasize the need for infrastructures of support needed for genuine community-university engagement that goes beyond instrumental approaches observed on many campuses.

Something else we have not fully grappled with in our work together, is the concept of 'intersectionality' itself. It is not an especially user-friendly term, and its definition is contested and ever-changing. The basic ideas of intersectionality have their roots in the everyday, bottom-up praxis of the marginalized (Cho, Crenshaw \& McCall, 2013; Chun, Lipsitz \& Shin, 2013). But the language itself can be alienating, and reinforce elitism. Some of the pillars of intersectionality might also need rethinking. One of its foundational principles is to start from the position of the most marginalized (Dhamoon \& Hankivsky, 2011). This was a central rationale for choosing income assistance as our pilot area for research: to prioritize poverty in our assessment of changing public services. However, as we started to talk through the complications of this work, our partners from the Canadian Federation of Students raised a compelling question. Since we were ultimately engaging in methodological experimentation by trying to adapt Multistrand Intersectional Policy Analysis to our context, what are the risks to the participants? Is this the most ethical approach? Perhaps we should test it out first in collaboration with a less vulnerable community to work out the major wrinkles?

There are also practical limits to doing intersectionality. Intersectionality is concerned with the process of policy making, ensuring that "the voices of vulnerable and marginalized individuals and groups be represented" and preventing "policies that are worked out for rather than with politically excluded constituencies (Hankivsky \& Cormier, 2011, pp. 219, 222). But what happens when the very people whose voices are most needed are least able to express them? In the case of our project, many of those most affected by changing public services were least likely to have the time and resources to participate. For instance, advocacy organizations working with Indigenous women and immigrant women have repeatedly told us that although this is an important project, they are just too stretched to be actively involved. Further, after multiple attempts, it was ultimately not possible to organize an African-Nova Scotian discussion group. The lack of voices of women from this particular community is a major limitation of this research, as African-Nova Scotian women have been on the front lines of expanding public services and ensuring universal access in the province. The reality is that there are structural impediments and limits to capacity that are beyond the reach of this project. Our CPS coordinators were funded for only three hours a week, and were working full-time jobs elsewhere.

The CPS group met regularly. Although the interest in the project was high in the beginning, with representatives from 17 different organizations attending our first meeting, that number later dipped to approximately seven to ten active groups. Each group's ability to participate in the project was directly connected to: their financial capacity to send paid staff; the structure of their organizations (as some only had volunteers who did not have the time); the nature of their work allowing time for anything outside of their core services; and their connection to the project. Since some groups could not see a direct link between the project and their 
work, CPS did not become a priority. Often people did not give their availability through online scheduling, reply to e-mails, or even phone calls because they simply do not have the time to add anything else to their schedules. This is unsurprising since the participants in our project were sought precisely because of their lived expertise on the impacts of austerity. Based on their experience with community-campus engagement, Kepkiewicz, Levkoe, and Brynne (2018) discuss the ways in which neoliberalization offloads greater responsibility for program delivery and restricts the political work of under-resourced non-profits.

There were a variety of challenges organizing a group as large and diverse as this. One was meeting times, since the commitments and ability of some members allow them to meet during the day as part of their work or they are retired, whereas others are volunteers or have work and commitments outside of their representative organizations. With such a large steering committee, there were often not the same people at every meeting, which made it difficult and time-consuming to get consensus on issues. We also struggled to continue to engage people without drawing an exact correlation between their work and what the CPS project was trying to achieve. What has become apparent is the complexity of the issues encompassed by CPS since there have been many different interpretations of what public services are, and how changes have affected a variety of constituencies.

\section{Opportunities}

At its heart, intersectionality is a means of collective struggle: "intersectional prisms can inform connections across privilege as well as subordination to better facilitate meaningful collaboration and political action" (Cho, Crenshaw \& McCall, 2013, p. 804). Hankivsky and Cormier (2011) add that,
there exists a unique 'challenge of creating complex alliances across intersecting inequalities.' At the same time, there has been increasing attention to exploring the potential of intersectionality as a coalition-building tool that unites individuals as they work toward a common agenda ... identifying 'spaces for shared mobilizations' in a common pursuit of social justice (p. 227).

This was exactly Goal 1 of CPS: to identify and develop tools, connections, agreements, and strategies for tracking changes to public services and public sector employment.

CPS had an explicitly political orientation toward nurturing broad-based networks and solidarity locally and nationally for social movement mobilization. With a communitydriven agenda and methodology drawn from feminist intersectionality, we were attempting to leverage academic resources for the purposes of community development and building advocacy capacity. The Nova Scotia cluster brought together different groups and fostered new conversations. We had some very rich discussions and had organizations around the same table that would not necessarily work together as partners in any other forum. A striking observation at our first meeting was the realization that many of the labour and community-based representatives in the room had rarely, if ever, met together. True to the 
spirit of intersectionality, CPS offered a "gathering place" for debate and collaboration (Cho, Crenshaw \& McCall, 2013, p. 788), where we could identify common challenges and strategies for change. We gave sustained focus to what we could work on collectively in the now and in the future. Some of this required facilitating very difficult conversations. But we believe it was worth the effort.

One of the contributions of intersectionality is that it urges us to problematize how we think about power and privilege. Power is always in flux. Hankivsky et al. (2012) emphasize that,

[i] $\mathrm{t}$ is important to recognize the relational nature of power - i.e., that a person can simultaneously experience both power and oppression in varying contexts and at varying times. These relations of power include experiences of power over others, but also that of power with others (power that involves people working together as collective actors). In recognizing the shifting intersections in which power operates, intersectionality moves beyond what Martinez (1993) terms the 'Oppression Olympics,' which occur when groups compete for the title of 'most oppressed' in order to gain political support, economic resources, and recognition. Intersectionality thus rejects an additive model of oppression that leaves the systems that create power differentials unchanged (pp. 35-36).

In the Changing Public Services project, intersectionality helped us to navigate vulnerability and risk. Let's consider our original plan to host dialogues on income assistance. The implicit assumption about the dynamic at play was that despite some shared harm caused by austerity to public sector workers and recipients, those on income assistance who are living in persistent poverty are distant from the centre of power and privilege. Further, many community-based workers in the sector (primarily women) are located in under-resourced, non-unionized, precarious employment situations. Conversely, those who deliver income assistance are government employees with union protection. Yet by participating in this research, public servants could face a direct risk in that their jobs could be jeopardized. ${ }^{6}$ Whereas in one context (service provision), public sector workers are in a position of power over their 'clients' in another context (research), they are vulnerable to the discipline and control of their employers. Even though it may be frustrating for some pragmatically-minded participants, by simply talking through various research methodologies, we learned important intersectional lessons. Clark et al. maintain that "investing time as a team to share your experiences/multiple locations, building a team that reflects the complexity of the community/issue you are entering and considering multiple locations from within and outside of various community locations" are critical to intersectional, community-based processes (p. 244).

Of course, this deliberative approach does not satisfy the immediate needs of participants, so the project was designed to work at multiple levels and timelines. Goal 2 was to: use

\footnotetext{
${ }^{6}$ Certainly those in voluntary sector service organizations face funding cuts on a regular basis, but this would be true regardless of their participation in the CPS project. Also, while increasingly under attack, advocacy is still seen as an acceptable part of their job.
} 
participatory tools to track and analyze the impacts of these changes on diverse groups of women over time (e.g. mapping, media analysis, storytelling). Alongside the regional activities, the national team was preparing several tools and resources that could be used by communities in the short term. These included, as outlined earlier: a study of the impacts of precarious employment on women in the public sector; an intersectional statistical analysis of women and employment; and a systematic literature review of the impacts of changing public services on women, with emphasis on young women, women with disabilities, Indigenous women, lone parents and immigrant women.

An integral piece of the national research, particularly the systematic literature review, was the collection of as many community-based resources as possible, which are being added to the project's research database. We compiled any materials produced by organizations, such as research papers, factsheets, and internal documents because this is essential to democratic knowledge production. Kepkiewicz, Levkoe, and Brynne (2018) note that communities "have experienced the academy as an elitist institution with rules and regulations that work to legitimize certain types of knowledge and knowers" (p. 47). CPS values the indispensable, and under-acknowledged research that is done in communities and contributes to the creation and dissemination of new knowledge.

In this study of the impacts of changes in public services, it was possible to capture both individual and shared experiences that advanced Goal 3: identify combined and cascading impacts as a result of municipal, provincial and federal changes. Although the presence of others may have discouraged some participants from sharing particular details, the openended framing of the questions was meant to create an environment where participants would work together to tell a story about how changes to public services have had an impact on women. Through our conversations, research participants made generous and thoughtful contributions, sharing intimate details about their lives while connecting their personal experiences to wider political and social concerns. They listened to each other and developed ideas in collaboration. In some groups, the conversations broke down at times into laughter or banter, but participants generally found their way back to the subject matter quickly. This research methodology clarified the voices of individual participants, while also highlighting moments when the group comes together in discussion to form what Janet Smithson calls a “jointly produced position” (2000). In some cases, groups started to strategize about how they might act together in the future. For instance, through their conversation at the Bridgewater Family Support Centre, the women started to plan an education session on the history of social assistance policy, speaking to Goal 4: collectively prioritize areas for further research and action.

Having nurtured these real connections in the community, we wanted to build on them with another pan-Canadian project, Engendering Public Engagement: Democratizing Public Space. This project was born out of discussions about the upcoming $50^{\text {th }}$ anniversary of the Royal Commission on the Status of Women. There was interest in exploring contemporary public engagement strategies that could connect with women whose voices are often un-or underrepresented in public policy. In Nova Scotia, our local initiative is called, Changing Public 
Engagement from the Ground Up. In partnership with our CPS network, we are 'testing' a variety of creative community-led public engagement exercises. So far, these include a sharing circle of Indigenous women giving their reflections on the Walking with Our Sisters memorial, an interactive activity about social inequality with girls and young women at Mount Saint Vincent University, a panel discussion with Deaf Women and Women with Disabilities, and a podcast with women in rural communities.

\section{Conclusion}

Both community-engaged and intersectional scholarship are flourishing, but often independently.

The CPS project, aimed at understanding women's diverse experiences with public services, was a unique experiment in intersectional community-based research. In the Nova Scotia region, through collaboration between academics, labour, and community activists, we developed a model for collective action and research. In our work together, as we explored the promise of "multistrand" intersectional policy analysis, we struggled with questions of power and privilege, academic culture and institutions, and community capacity. Communitybased networks are not immune from hierarchies between academics, between academics and community partners, and between community partners. Kepkiewicz, Levkoe, and Brynne (2018) make the important point that researchers must think carefully about "who community includes and whose communities are prioritized," as well as the diverse needs of differently situated community partners and the bias toward formal organizations over informal actors (53). We must be constantly mindful of inaccessible, inappropriate and/or exclusionary academic language, categories, cultures, expectations, processes, and methodologies.

We cannot expect individual research projects, no matter how well-intentioned or considered, to overcome institutionalized and structural social inequalities (Kepkiewicz, Levkoe \& Brynne, 2018). Still, through CPS we were able to cultivate some new terrain for participatory policy analysis and advocacy that can be mobilized to resist austerity and to imagine alternatives. The project used academic resources to connect community partners and prompt conversations that were not happening otherswise in service of collective analysis and organizing. It revealed greater complexities in how and where power operates. It took seriously the responsibility of academics to make research useful and accessible to community and to advance multiple forms of knowledge. Through these learnings, we can being to shape a community-based intersectionality. 


\section{About the Authors}

Michele Cohen is the national education representative of the Atlantic region for the Canadian Union of Public Employees (CUPE) Nova Scotia, Newfoundland and Labrador. She was the community Co-Initiator on the Changing Public Services Project.

Tammy Findlay (corresponding author) is an associate professor and chair in the department of political and Canadian studies at Mount Saint Vincent University. Her research interests are related to feminist intersectionality and social policy, child care, women's representation and democratic governance. She was the academic co-initiator on the Changing Public Services Project. Email: Tammy.Findlay@msvu.ca

Mary-Dan Johnston is a writer, researcher and activist in Halifax, Nova Scotia, and a Rhodes Scholar with a Master's of Arts from the University of Oxford. She was the coordinator of the Changing Public Services Project.

\section{References}

Andrée, P., Findlay, I., \& Peacock, D. (2018). Transformations through 'Community-First' engagement. Engaged Scholar Journal, 4(2), i-x.

Brodie, J., \& Bakker, I. (2017). Canada's Social Policy Regime and Women: An Assessment of the Last Decade. Ottawa: Status of Women Canada, 2007. Retrieved from http://www.swc-cfc.gc.ca/pubs/ pubspr/0662450870/2007039780662450870_e.pdf

Canada. Clerk of the Privy Council. (2014). Public Service Renewal. Oct. 2. Retrieved from http://www. clerk.gc.ca/eng/feature.asp?pageId=73

Canada. Clerk of the Privy Council. (2012). Moving Ahead: Public Service Renewal in a Time of Change. Prime Minister's Advisory Council on the Public Service: Sixth Report to the Prime Minister. March. Retrieved from http://www.clerk.gc.ca/local_grfx/docs/pmacccpm/6-2012-eng.pdf

Canada. Public Service Commission. (2008). The 100 years of the Public Service Commission of Canada 1908-2008. July. Retrieved from http://www.psc-cfp.gc.ca/abt-aps/tpschcfp/hist-eng.pdf

Canadian Research Institute for the Advancement of Women (CRIAW). (2014). Changing Public Services. Ottawa. Retrieved from http://www.criaw-icref.ca/en/page/changing-publicservices

Canadian Research Institute for the Advancement of Women (CRIAW). (2006). Intersectional Feminist Frameworks. Ottawa. Retrieved from http://criawicref.ca/sites/criaw/files/IFFs\%20Primer. pdf

Cho, S., Crenshaw, K.W., \& McCall, L. (2013). Toward a field of Intersectionality Studies: Theory, applications, and praxis. Signs, 38(4), 785-810. 
Chun, J., Lipsitz, G., \& Shin, Y. (2013). Intersectionality as a social movement strategy: Asian immigrant women advocates. Signs, 38(4), 917-940.

Clark, N., Hunt, S., Jules, G., \& Good, T. (2010). Ethical dilemmas in community-based research: Working with vulnerable youth in rural communities. Journal of Academic Ethics, 8(4), 243252.

Cohen, M.G., \& Pulkingham, J. (Eds.). (2009). Public Policy for Women: The State, Income Security, and Labour Market Issues. Toronto: University of Toronto Press.

Dorow, S., \& Smith Acuña, N. (2015). Community engagement in the humanities, arts, and social sciences: Academic dispositions, institutional dilemmas. Engaged Scholar Journal, 1(1), 51-68.

Dhamoon, R., \& Hankivisky, O. (2011). Why the Theory and Practice of Intersectionality Matter to Health Research and Policy. In O. Hankivksy (Ed.), Health Inequities in Canada: Intersectional Frameworks and Practices (pp. 16-50). Vancouver: UBC Press.

Four Worlds Centre for Development Learning. (2000). The Community Story Framework: A Tool for Participatory Community Analysis. Cochrane, AB: Four Worlds Centre for Development Learning.

Gregory, T., Betzen, D., Elias-Rodas, D., Thomas, M., \& Augustin, T. (2008). Guiding principles for youth civic engagement. The Community Psychologist, 41(3/4), 62-65.

Hankivsky, O., \& Cormier, R. (2011). Intersectionality and public policy: Some lessons from existing models. Political Research Quarterly, 64(1), 217-229.

Hankivsky, O. et al. (2012). Intersectionality-Based Policy Analysis. In O. Hankivsky (Ed.), An Intersectionality-Based Policy Analysis Framework (p. 33-46). Vancouver: Institute for Intersectionality Research and Policy, Simon Fraser University.

Institute of Public Administration of Canada (IPAC). (2013). An Armchair Discussion on Public Service Renewal. Nova Scotia Regional Group of the Institute of Public Administration of Canada (IPAC) and Nova Scotia Federal Council.

International Centre for Parliamentary Studies (ICPS). (2012). Public Sector Reform. Retrieved from http://www.parlicentre.org/Public_Sector_Reform.php

Kepkiewicz, L., Levkoe, C.Z., \& Brynne, A. (2018). “Community First” for whom? Reflections on the possibilities and challenges of community-campus engagement from the Community Food Sovereignty Hub. Engaged Scholar Journal, 4(2), 43-60.

Ontario. Commission on the Reform of Ontario's Public Services. (2012). Public Services for Ontarians: A Path to Sustainability and Excellence. Retrieved from http://www.fin.gov.on.ca/en/ reformcommission/chapters/report.pdf

Parken, A., \& Young, H. (2007). Integrating the Promotion of Equality and Human Rights for All. Unpublished Report for Welsh Assembly Government and Equality and Human Rights Commission.

Professional Institute of the Public Service of Canada (n.d.). The Big Chill: Silencing Public Interest Science, A Survey. Retrieved from http://www.pipsc.ca/portal/page/portal/website/issues/ science/bigchill

Ross, S. (2008). Social Unionism and membership participation: What role for Union Democracy? Studies in Political Economy, 81, 129-157.

Smithson, J. (2000). Using and analysing focus groups: Limitations and possibilities. International Journal of Social Research Methodology, 3(2), 103-119. 
United Nations. United Nations Economic Commission for Africa (UNECA) (2010). Innovations And Best Practices in Public Sector Reforms: The Case of Civil Service in Ghana, Kenya, Nigeria and South Africa. December.

Voices-Voix. Silencing the Public Service (n.d.). Retrieved from http://voices-voix.ca/en/facts/ attacks-on-the- public-service

Waddell, S. (2012). Global finance as an action research domain: Testing the boundaries. Action Research, 10(1), 40-60. 